\title{
Malignant Phyllode Tumour with Heterologous Sarcomatous Differentiation - A Rare Case Report
}

\author{
Anup Shivom Kediya ${ }^{1}$, Anil Kalyandas Agrawal' ${ }^{2}$, Arvind Shridharrao Bhake ${ }^{3}$, Obaid Noman ${ }^{4}$ \\ 1, 2, 3, 4 Department of Pathology, Jawaharlal Nehru Medical College, Datta Meghe \\ Institute of Medical Sciences, Sawangi (Meghe), Wardha, Maharashtra, India.
}

\section{INTRODUCTION}

Malignant phyllode tumour is a lesion of rare occurrence in breast and malignant phyllodes tumour with heterologous sarcomatous differentiation is still rarer. Heterologous sarcomatous differentiation with more than three morphological differentiation has rarely been reported. This case report addresses heterologous sarcomatous differentiation in a malignant phyllodes tumour for its morphological rarity confirmed with immunohistochemistry.

Cancer of breast affects one in nine women and is the second most common cause of deaths related to cancer in women. ${ }^{1}$ Phyllodes tumour was described in 1774 , the condition was properly defined in $1838 .^{2}$ One of the rarest tumour is cystosarcoma phyllodes (CSP) which can be seen in $0.3-0.9$ percent of all breast tumours and in 2 - 3 percent of fibro-epithelial tumors. ${ }^{1}$ Phyllodes tumour can only be found in mammary tissue and on histology they have a component of epithelial as well as metaplastic mesenchymal origin. ${ }^{3}$ Grading of phyllodes tumour into benign, borderline and malignant depends on a congregation of histopathological characters that include degree of stromal hypercellularity, mitotic activity and cytologic atypia, circumscribed vs. invasive margins and stromal overgrowth. ${ }^{4}$ On histology, malignant phyllode tumours may show significant heterogeneity in morphology such as fibrosarcomatous, lipo-sarcomatous, chondro-sarcomatous, rhabdomyosarcomatous, or osteo-sarcomatous differentiation. ${ }^{5}$

\section{PRESENTATION OF CASE}

An 80 years old female presented with a lump in left breast since five months which was progressive in size and painful since one month. She didn't have any past history or family history of breast tumours. On local assessment, lump which was well defined was observed involving the outer upper \& lower quadrant of left breast. Lump was $5 \times 4 \mathrm{~cm}$. in size, freely mobile, tender and hard in consistency. Skin over the lump was ulcerated and local temperature was raised. On palpation, axillary lymph nodes were not palpable and no lump was palpated in contralateral breast. Mammography showed an irregular lesion with calcifications which were coarse in nature in left breast. Breast aspiration cytology yielded insufficient diagnostic material. Laboratory findings were found to be within the normal limits. X-ray chest showed a well-defined bony mass in the breast which was not attached to ribs and no signs of metastasis were seen. Intraoperative examination confirmed all the findings of local examination. Lump demonstrated no evidence of adhesion to chest wall and underlying muscles. No evidence of enlargement of axillary lymph node was seen intraoperatively. Under general anaesthesia modified radical mastectomy was performed.
Corresponding Author: Dr. Anil Kalyandas Agrawal, Snehal Nagar, Sewagram Road, Wardha, Maharashtra, India. E-mail: dranilagrawal.456@gmail.com

DOI: $10.14260 / \mathrm{jemds} / 2021 / 52$

How to Cite This Article:

Kediya AS, Agrawal AK, Bhake AS, et al. Malignant phyllode tumour with heterologous sarcomatous differentiation a rare case report. J Evolution Med Dent $S c i$ 2021;10(04):240-242, $10.14260 / \mathrm{jemds} / 2021 / 52$

DOI:

Submission 12-09-2020,

Peer Review 24-11-2020,

Acceptance 30-11-2020,

Published 25-01-2021.

Copyright (C) 2021 Anup Shivom Kediya et al. This is an open access article distributed under Creative Commons Attribution License [Attribution 4.0 International (CC BY 4.0)] 


\section{PATHOLOGICAL DISCUSSION}

On gross examination, the modified radical mastectomy specimen showed mass of size $5 \times 4 \times 3 \mathrm{~cm}$. covered with skin showing ulceration. During grossing, gritty sensations were heard. Hard bony mass of size $3 \mathrm{~cm}$. in diameter was identified in the main mass \& submitted for decalcification. Cut surface of the mass was greyish white to tan and glistening with foci of necrosis. Extensive sectioning was done.

On microscopic examination, classical features of cystosarcoma phyllodes leaf like spaces lined by normal duct epithelium with marked stromal over-growth, necrosis, congested \& proliferated blood vessels were seen. Approximately 6 - 7 mitoses / 10 high power field (HPF) were seen in this area. Tumour tissue composed of oval to spindle cells with hyperchromatic \& pleomorphic nuclei were also seen. At places, tumour giant cells were also seen. Tumour margins were infiltrative and surgical margins were free of tumour infiltration (Figure 1). On narrow observation, the stroma exhibited four characteristic and distinct malignant mesenchymal tumour elements: fibrosarcomatous pattern (Figure 2), chondrosarcomatous (Figure 3), osteosarcomatous (Figure 4) \& liposarcomatous differentiation.
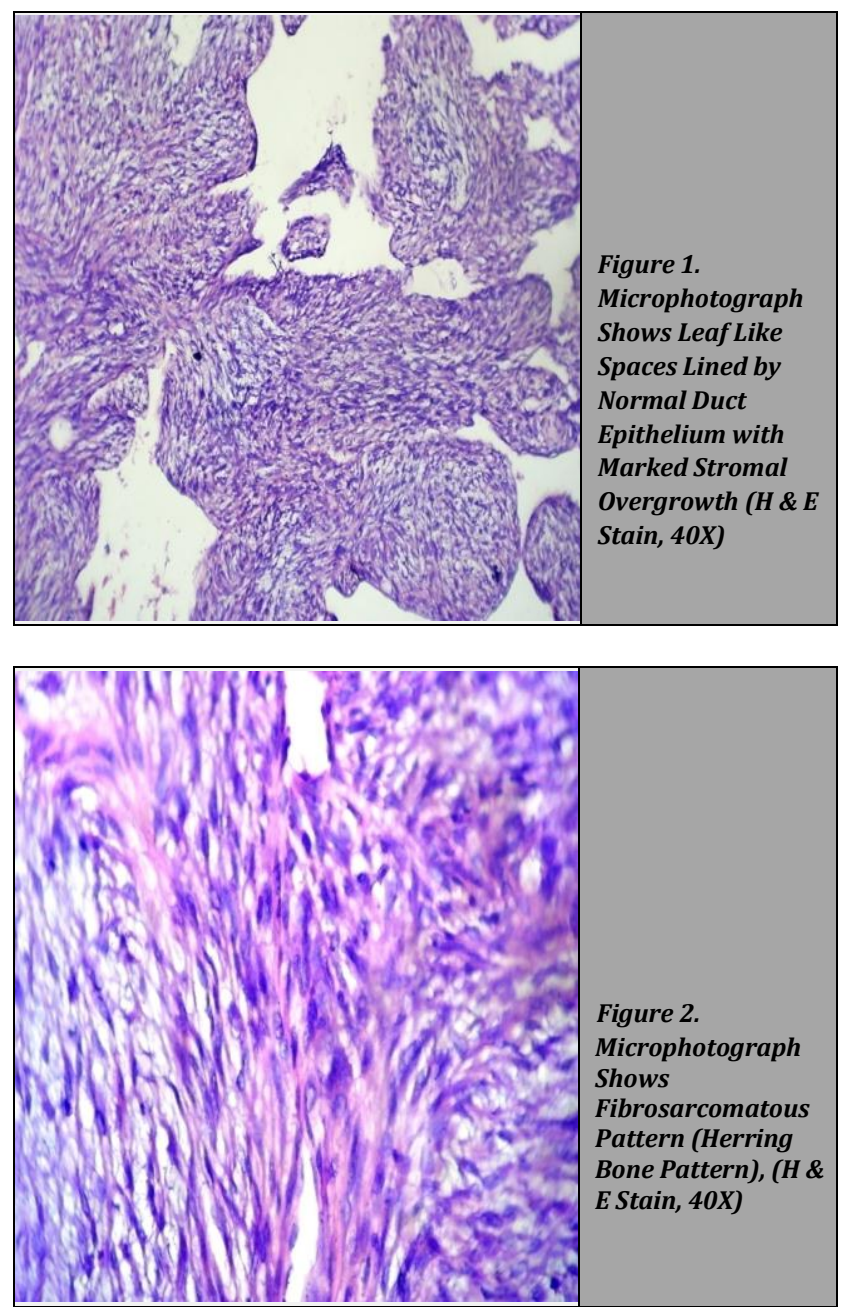

On immunohistochemistry, tumour was positive for vimentin as well as S-100 (Figure 5) and negative for epithelial membrane antigen and cytokeratin in areas of sarcomatous differentiation.
Evidence of the lymph node metastasis or a systemic spread following total surgical excision of the tumour was not found, and close follow-up was recommended.
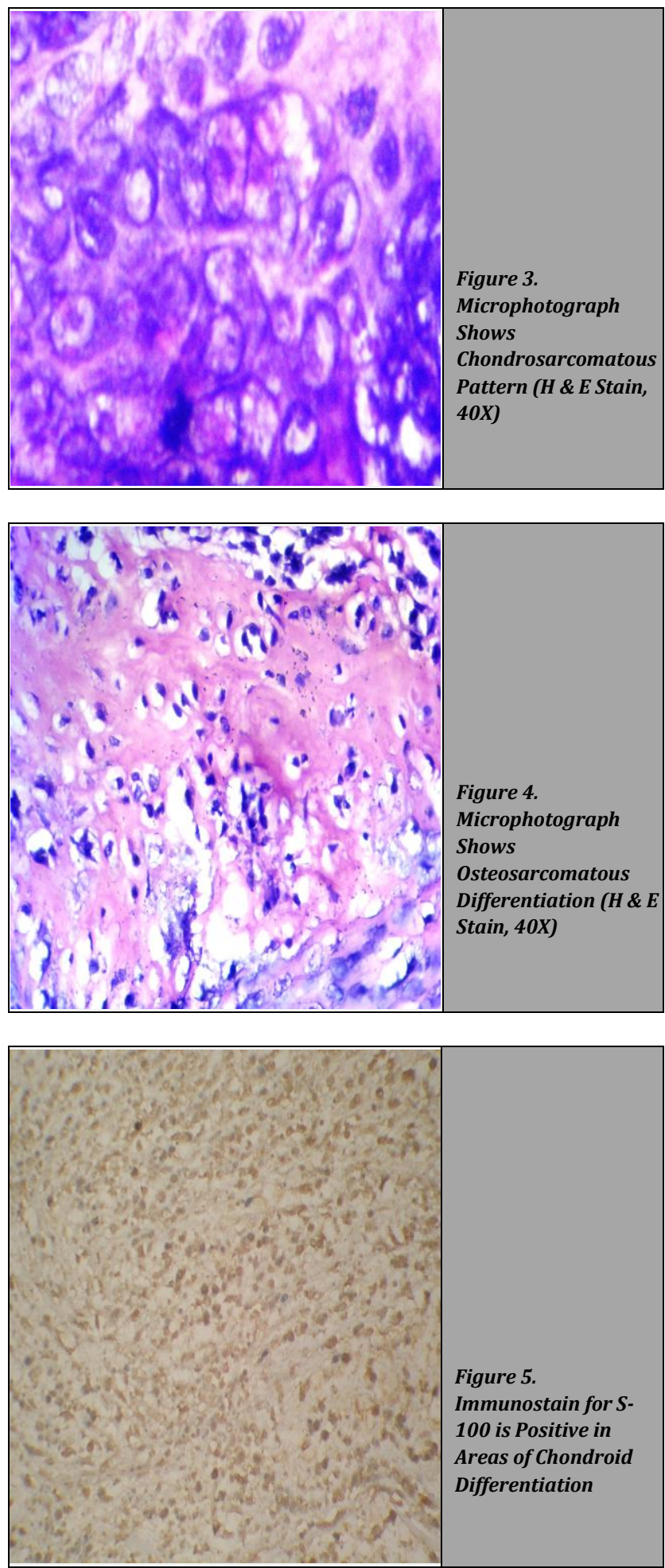

\section{DISCUSSION}

Phyllodes tumours are uncommon tumours that account for less than 1 percent of all breast neoplasms. ${ }^{5}$ Sarcomatous differentiation is very rare finding in phyllode tumour. The most common histologic type is lipo-sarcoma, malignant fibrous histiocytoma, rhabdomyosarcoma and 
chondrosarcoma. An even more unusual event is sarcomatous overgrowth with multiple histologic types. ${ }^{1}$ To our knowledge only five cases of malignant phyllodes tumour with associated multiple sarcomatous components were reported.

In present case liposarcomatous and fibrosarcomatous differentiation are reported which are similar to cases reported by De Luca et al $^{6}$ and Guerreroa et al. ${ }^{1}$

Bujas et $\mathrm{al}^{7}$ reported liposarcoma in addition with osteosarcoma and chondrosarcoma, the same had also been reported by Garcia et $\mathrm{al}^{8}{ }^{8}$ Mohammed et $\mathrm{al}^{3}$ and is in accordance with the findings of present case. Studies on carcinoma breast were also reported by Anand et al, ${ }^{9}$ Lamture et al. ${ }^{10}$ Malignant lesions show the typical characteristics like autofluorescence ${ }^{11}$ and specified immunohistochemical profiles.12 Haematogenous spread of cancers from other regions can be tracked.13,14 Ghavat et al reported malignant transformation of solitary cylindroma involving the frontonasal region. ${ }^{15}$ Few studies have investigated the different therapeutic aspects of cancers. ${ }^{16,17}$

Other heterologous differentiation reported were malignant fibrous histiocytoma by Garcia et $\mathrm{al}^{8}$ and Mohammed Al-Zoubaidi et $\mathrm{al}^{3}{ }^{3}$ rhabdomyosarcoma and leiomyosarcoma by Guerreroa et $\mathrm{al}^{1}$ and anaplastic and giant cell sarcomas by De Luca et al. ${ }^{6}$

Negative cytokeratin and positive vimentin staining was confirmed by immunohistochemistry (IHC) in reported case, which suggested that the origin of tumour was not from epithelial cells of the breast. S-100 was also positive in areas of chondroid differentiation suggesting heterologous sarcomatous differentiation.

Evidence of components of epithelial malignancy was not found so the diagnosis of malignant phyllode tumour was made with associated fibrosarcomatous pattern, chondrosarcomatous, osteosarcomatous \& liposarcomatous differentiation in the present case.

Treatment for all phyllode tumour requires a minimum of $1 \mathrm{~cm}$ clearance of margin at surgery as per standards. As malignant phyllode tumour rarely shows metastasis to regional lymph nodes, there is no indication for sentinel node biopsy. Use of routine adjuvant radiation therapy and / or chemotherapy is not recommended for malignant phyllode tumour since neither has proven to show an improvement in survival. ${ }^{3}$

Heterologous sarcomatous differentiation though reported in past is a rare histopathological phenomenon in malignant phyllode tumour. The consultant pathologist should have helpful recall of this fact at reporting as it may lead to misinterpretation of primary pathology. Immunohistochemistry resolves the dilemma of sarcomatous differentiation consistently in malignant phyllode tumour from metaplastic carcinoma of breast.

Financial or other competing interests: None.

Disclosure forms provided by the authors are available with the full text of this article at jemds.com.

\section{REFERENCES}

[1] Guerreroa MA, Ballardb BR, Graua AM. Malignant phyllodes tumor of the breast: review of the literature and case report of stromal overgrowth. Surg Oncol 2003;12(1):27-37.

[2] Rosen PP. Fibroepithelial neoplasms. In: Rosen PP, ed. Rosen's Breast pathology. $3^{\text {rd }}$ edn. Lippincott Williams \& Wilkins 2009: p. 202.

[3] Al-Zoubaidi M, Qiu S, Bonnen M, et al. Malignant phyllodes tumor of the breast: a case report. The Open Breast Cancer Journal 2011;3:45-8.

[4] Uriev L, Maslovsky I, Vainshtein P, et al. Malignant phyllodes tumor with heterologous liposarcomatous differentiation and tubular adenoma-like epithelial component. Int J Med Sci 2006;3(4):130-4.

[5] Küçük U, Bayol U, Etit D, et al. Malignant phyllodes tumor of the breast with osteosarcomatous differentiation. J Breast Health 2013;9:88-91.

[6] De Luca LA, Traiman P, Bacchi CE. An unusual case of malignant cystosarcoma phyllodes of the breast. Gynaecol Oncol 1983;24(1):91-6.

[7] Bujas T, Lucijanić MM, Tomić L, et al. Malignant phyllodes tumor with three different sarcomatous components - a case report. Acta Clinica Croatica 2006: p. 150-1.

[8] Garcia FU, Soans S, Galindo LM. Malignant phyllodes tumor with chondrosarcomatous differentiation: report of a case with cytological presentation. Diagn Cytopathol 1999;20(4):241-5.

[9] Anand AS, Shinde RK. To compare the effects of adjuvant and neoadjuvant chemotherapy on outcome of stage III carcinoma breast. J Evolution Med Dent Sci 2020;9(8):496-501.

[10] Lamture YR, Salunke B, Shahabuddin MD. Carcinoma of breast-a study profile. Journal of Evolution of Medical and Dental Sciences 2018;7(45):4857-61.

[11] Bagri-Manjrekar K, Chaudhary M, Sridharan G, et al. In vivo autofluorescence of oral squamous cell carcinoma correlated to cell proliferation rate. Journal of Cancer Research and Therapeutics 2018;14(3):553-8.

[12] Jagtap MM, Shukla S, Acharya S, et al. Utility of histochemical and immunohistochemical profile in grading of squamous cell carcinoma of the oral cavity. Journal of Clinical and Diagnostic Research 2020;14(1):EC1-5.

[13] Panchbhai A, Bhowate R. MRI evaluation of involvement of parotid and submandibular glands by tongue squamous cell carcinoma. Oral Oncol 2020;102:104557.

[14] Gupte M, Jadhav U, Ghewade B, et al. To study the incidence of lung cancer in patients of newly and previously diagnosed chronic obstructive pulmonary disease at AVBRH. Medical Science 2020;24(102):658-63.

[15] Ghavat C, Bhola N, Jadhav A, et al. Malignant transformation of solitary cylindroma involving the frontonasal region- a rarity. Journal of Clinical and Diagnostic Research 2020;14(4):ZD1-4.

[16] Mathur A, Rastogi N, Gurjar D, et al. Safety and efficacy of weekly versus three-weekly paclitaxel plus platinum neoadjuvant chemotherapy in patients with locally advanced squamous cell head and neck carcinoma: a pilot study. South Asian J Cancer 2018;7(4):254-7.

[17] Khatib MN, Gaidhane A, Gaidhane S, et al. Ghrelin as a promising therapeutic option for cancer cachexia. Cell Physiol Biochem 2018;48(5):2172-88. 